\title{
CROSS-RESISTANCE TO THYMIDYLATE SYNTHASE INHBITORS IN P-GLYCOPROTEIN AND NON-P-GLYCOPROTEIN CELL LINES
}

\author{
B. van Triest, F. Telleman, H.M. Pinedo, \\ C.L. van der Wilt, G.J. Peters \\ Free University Hospital \\ Department of Medical Oncology \\ po box 7057 \\ $1007 \mathrm{MB}$ Amsterdam \\ The Netherlands
}

\section{INTRODUCTION}

The fluoropyrimidines have been used for the treatment of patients with solid tumors of the breast, head and neck, and gastrointestinal tract. Although the response to treatment is not impressive 5-fluorouracil $(5 \mathrm{FU})$ is part of the standard protocols in advanced colorectal cancer ${ }^{1,2}$. The mechanism of action of $5 \mathrm{FU}$ is rather complicated and may consist of: 1 . incorporation into DNA; 2 . incorporation into RNA; and 3. inhibition of thymidylate synthase (TS) leading to inhibition of DNA synthesis due to lack of thymidylate formation. Various mechanisms of resistance against 5FU have been described; some are associated with alterations in the 5FU metabolism, some with inhibition of TS (e.g. relative intracellular folate depletion) and mutations or increased TS levels. Chu et al. found cross-resistance to 5FU in Multi Drug Resistant (MDR) human breast and human colon cell lines which showed a significant overexpression of $\mathrm{TS}^{3}$. Zhang et al. found cross-resistance to $5 \mathrm{FU}$ and 5-fluoro-2'-deoxy-uridine in MCF7/Adr cells caused by increased level of $\mathrm{TS}^{4}$. In these studies only cell lines with MDR due to overexpression of P-glycoprotein (P-gp) have been studied; however, no study has been performed on possible cross-resistance in cell lines with a MDRphenotype not due to an overexpression of P-gp. We selected a panel of three cell lines, the wild type SW1573 and two doxorubicin (DOX) resistant cell lines; a MDR variant resistant to DOX due to P-gp overexpression (SW1573/2R160) and a subline resistant to DOX but with no P-gp overexpression (SW1573/2R120). In these cell lines we determined whether they exhibit a cross-resistance to $5 \mathrm{FU}$. 
We also determined a possible cross-resistance to several TS-inhibitors with different structural properties; ZD1694 (Tomudex) an antifolate dependent on transport via the reduced folate carrier and a good substrate for folylpolyglutamate synthetase; and AG337 a lipophilic compound, transported by passive diffusion which can not be polyglutamylated.

\section{MATERIALS AND METHODS}

SW1573 is a squamous cell carcinoma cell line of the lung. The two resistant sublines were selected by culture in increasing doxorubicin concentrations ${ }^{5,6,7}$. Cells were cultured under standard conditions. All experiments were carried out after a drug free period of at least 7 days.

Chemosensitivity was determined using the Sulforhodamine B (SRB) assay as described previously ${ }^{8,9}$. Drug exposure was $72 \mathrm{hr}$. The $\mathrm{IC}_{50}$ was the concentration that is equal with half-maximal growth of the control cells based on the difference of optical density values at day 0 and day 4 of drug exposure. The $\mathrm{IC}_{50}$ concentrations were based on at least three separate experiments.

TS assays (FdUMP binding assay and TS catalytic assay) were performed as described previously ${ }^{10,11,12}$. The procedure for immunohistochemical staining for TS has been described elsewhere ${ }^{13}$. Western blotting of the TS protein was performed according to a standard method ${ }^{14}$. The TS antibody was a generous gift of Dr. G.W. Aherne, Institute of Cancer Research, Sutton, Surrey, United Kingdom.

Flow-cytometry to determine the cell-cycle distribution was performed essentially according to Vindelov and Christensen ${ }^{15}$.

\section{RESULTS}

\section{Growth inhibition studies}

Growth inhibition experiments confirmed the cross-resistance pattern for DOX previously observed with the MTT-assay ${ }^{5}$. In the $2 \mathrm{R} 120$ a collateral sensitivity was observed for 5FU and AG337 but a cross-resistance for ZD1694. 2R160 cells showed cross-resistance to all drugs.

Table 1. Growth inhibitory effect of 5FU, folate-based TS inhibitors and DOX against non-P-gp (2R120) and P-gp (2R160) cell lines.

\begin{tabular}{llll}
\hline & & \multicolumn{2}{c}{ Cell lines } \\
\hline & SW1573 & 2R120 & 2R160 \\
& $\mathrm{IC}_{50}$ & $\mathrm{RF}$ & $\mathrm{RF}$ \\
\hline 5FU & $3.65 \pm 0.66$ & 0.4 & 2.4 \\
ZD1694 & $0.036 \pm 0.003$ & 8.8 & 18.8 \\
AG337 & $4.5 \pm 0.46$ & 0.7 & 17 \\
DOX & $0.069 \pm 0.012$ & 8.9 & 73 \\
\hline
\end{tabular}

The cell lines were exposed to 5FU, ZD1694, AG337 and DOX for $72 \mathrm{hr}$. $\mathrm{IC}_{50}$ values $(\mu \mathrm{M})$ are means \pm $\mathrm{SE}$ from at least 3 experiments performed in triplicate. Resistance Factor $(R F)=\mathrm{IC}_{\text {SOresist }} / \mathrm{IC}_{\text {SOwild typo }}$ determined per experiment. 


\section{TS assays}

Since TS is a common target for the three drugs we determined whether TS expression could explain these results. TS activity as measured by the FdUMP binding assay showed a slight increase of 1.5 fold in the $2 \mathrm{R} 120$ but a decrease of 0.7 in the 2R160 compared to the parental cell line SW1573 (Table 2).

The TS catalytic activity (conversion of dUMP to TMP) did not show significant changes. Evaluation of the expression of TS protein using immunohistochemical staining (IHC) revealed contrasting results, a high expression was found in the parental cell line and the 2R160 and a low expression in the 2R120 cell line.

Since both 5FU and ZD1694 have been reported to induce overexpression of TS $^{3}$, ${ }^{16}$ we determined whether this phenomenon might contribute to the observed resistance pattern. Treatment with 5FU showed an increase in TS protein level only in the 2R120 (Table 3); but ZD1694 induced an increase in all cell lines. AG337, however, decreased the TS protein level in the parental cell line, while in the 2 R120 the TS protein level was increased.

Table 2. TS levels in non-P-gp (2R120) and P-gp (2R160) cell lines.

\begin{tabular}{cccc}
\hline Cell line & $\begin{array}{c}\text { FdUMP binding } \\
\text { assay }^{\mathrm{a}}\end{array}$ & $\begin{array}{c}\text { TS catalytic } \\
\text { assay }^{\mathrm{b}}\end{array}$ & IHC \\
\hline SW1573 & $328 \pm 146$ & $209 \pm 4$ & +++ \\
2R120 & $477 \pm 159$ & $253 \pm 63$ & + \\
2R160 & $237 \pm 109$ & $202 \pm 44$ & +++ \\
\hline
\end{tabular}

Results are means $\pm S E$ of three scparate experiments. $a=$ FdUMP binding assay: $\mathrm{fmol} / 10^{6}$ cells. $\mathrm{b}=$ TS catalytic assay: pmol ${ }^{3} \mathrm{H}-\mathrm{H}_{2} \mathrm{O} / \mathrm{hr} / 10^{6}$ cells.

Table 3. Western immunoblot analysis in a non-P-gp (2R120) and P-gp (2R160) cell lines after treatment with 5FU and TS-inhibitors.

\begin{tabular}{lccc}
\hline & & Cell line & \\
\hline & SW1573 & 2R120 & 2R160 \\
\hline SFU & $100 \% \pm 3$ & $155 \% \pm 38$ & $111 \% \pm 50$ \\
ZD1694 & $143 \% \pm 16$ & $336 \% \pm 44$ & $148 \% \pm 24$ \\
AG337 & $70 \% \pm 12$ & $189 \% \pm 39$ & $96 \% \pm 13$ \\
\hline
\end{tabular}

Cells were exposed at their $\mathrm{IC}_{50}$ for $24 \mathrm{hr}$, thereafter Western blotting was performed. The amount of protein was related to that of the untreated cells. Quantitation was performed by densitometric scanning. Values are means $\pm S E$.

\section{Cell cycle distribution}

Since TS is a cell cycle related protein, we determined the cell-cycle distribution of untreated and treated cells. These experiments showed a similar S-phase distribution in all three cell lines. Treatment with ZD1694 resulted in a decrease in S-phase cell percentage in SW1573 and 2R120; but an increase in the 2R160. Treatment with 5FU showed a different pattern, decrease of S-phase cell percentage in all cell lines compared with the untreated cell lines. 
Table 5. Cell cycle distribution of non-P-gp (2R120) and P-gp (2R160) cell lines before and after treatment with 5FU and ZD1694.

\begin{tabular}{lccc}
\hline & \multicolumn{3}{c}{ \% cells in S-phase } \\
\hline & SW1573 & 2 R120 & 2R160 \\
\hline control & $34 \%$ & $38 \%$ & $34 \%$ \\
5FU & $14 \%$ & $23 \%$ & $30 \%$ \\
ZD1694 & $27 \%$ & $28 \%$ & $47 \%$ \\
\hline
\end{tabular}

Cells were treated for $24 \mathrm{hr}$ at their $\mathrm{IC}_{50}$ concentration. Thereafter cell cycle distribution was determined.

\section{DISCUSSION}

In this paper we demonstrated a cross-resistance to 5FU and to two TS-inhibitors in cell lines with a P-gp mediated MDR, however in the non-P-gp MDR cell line only cross-resistance was observed to ZD1694 but collateral sensitivity to 5FU and AG337. Elevation of the TS enzyme expression as observed in the studies of $\mathrm{Chu}_{\mathrm{et}} \mathrm{al}^{4}$, was not found.

The cross-resistance shown in the P-gp cell line (2R160) and the collateral sensitivity as well as cross-resistance in the non-P-gp cell line (2R120) for TS-inhibitors was striking. The compounds being tested have different characteristics; lipophilic (AG337) or non-lipophilic (ZD1694) with consequences for the mechanism of transport across the cell membrane. To exclude the influence of the P-gp drug efflux pump experiments were performed with verapamil which can inhibit competitively the P-gp mediated efflux. In our study reversal of the antifolate cross-resistance by verapamil could not be established (data not shown).

The 2R120 cell line showed cross-resistance to ZD1694 but collateral sensitivity to AG337. This is suggestive for a polyglutamylation defect because only ZD1694 has to be polyglutamylated to exert its intracellular activity. Since a defect of polyglytamylation has been described as a mechanism of resistance to antifolates, we will determine the polyglutamylation pattern in all cell lines.

Both $5 \mathrm{FU}$ and the folate-based TS inhibitors increased the TS expression in the 2R120 cell line, but in the parental and 2R160 only ZD1694 increased the expression of TS-protein. In order to determine whether this is related to alterations in translation or transcription of the TS gene we will determine the mRNA expression as described previously ${ }^{17}$. Gene amplification is thought to be a mechanism of drug resistance for TS-dependent chemotherapeutic agents ${ }^{18}$. Such studies will give evidence whether the differences between the cell lines will be at (post)transcriptional level, such as has been described by Chu et $\mathrm{al}^{3}$ and Keyomarsi et al. ${ }^{16}$.

The regulation of TS enzyme is cell cycle dependent and the enzyme is mainly active in the $S$-phase ${ }^{19}$. Our cell cycle distribution analysis showed a comparable amount of cells in the S-phase in the untreated SW1573, 2R120 and 2R160. So, the selective treatment with doxorubicin in the $2 \mathrm{R} 120$ and the $2 \mathrm{R} 160$ did not influence the cell cycle distribution. Treatment with 5FU and ZD1694 showed a different cell cycle distribytion pattern indicating that the mechanisms of action of both drugs are different.

We can conclude that a different pattern in collateral sensitivity and crossresistance to 5FU and antifolate TS-inhibitors could be observed in non-P-gp (SW1573/2R120) and P-gp (SW1573/2R160) cell lines. 


\section{ACKNOWLEDGMENTS}

This project was supported by a grant from the Netherlands Cancer Society, grant number VU-IKA 93-627.

\section{REFERENCES}

1. HM Pinedo and GJ Peters, Fluorouracil: biochemistry and pharmacology, J. Clin. Oncol. 6:16531664 (1988).

2. GJ Peters, CJ Van Groeningen, Clinical relevance of biochemical modulation of 5-fluorouracil, Ann. Oncology 2:469-480 (1991).

3. E Chu, JC Drake, DM Koeller et al., Induction of thymidylate synthase associated with multidrug resistance in human breast and colon cancer cell lines. Mol. Pharm. 39:136-143 (1991).

4. ZG Zhang, A Harstrick and YM Rustum, Mechanisms of resistance to fluoropyrimidines, Sem. in Oncol. 19; suppl 3:4-9 (1992).

5. CM Kuiper, HJ Broxterman, F Baas et al., Drug transport variants without P-glycoprotein overexpression from a human squamous lung cancer cell line after selection with doxorubicin, $J$. Cell. Pharm. 1:35-41 (1990).

6. F Baas, APM Jongsma, HJ Broxterman et al., Non-P-glycoprotein mediated mechanism for multidrug resistance precedes P-glycoprotein expression during in vitro selection for doxorubicin resistance in a human lung cancer cell line, Cancer Res. 50:5392-5398 (1990).

7. HG Keizer, GJ Schuurhuis, HJ Broxterman et al., Correlation of multidrug resistance with decreased drug accumulation, altered subcellular drug distribution, and increased P-glycoprotein expression in cultured SW-1573 human lung tumor cells, Cancer Res. 49:2988-2993 (1989).

8. P Skehan, R Storeng, D Scudiero et al. New colorimetric cytotoxicity assay for anticancer-drug screening, J Nath Cancer Inst 82:107-112 (1990).

9. YP Keepers, PE Pizao, GJ Peters et al., Comparison of the sulforhodamine B protein and tetrazolium (MTT) assays for in vitro chemosensitivity testing, Eur J Cancer 27:897-900 (1991).

10. GJ Peters, E Laurensse, A Leyva et al., Sensitivity of human, murine and rat cells to 5-fluorouracil and 5'-deoxy-5-fluorouridine in relation to drug metabolizing enzymzes, Cancer Res, 46:20-28 (1986).

11. CL Van der Wilt, HM Pinedo, K Smid et al., Elevation of TS following 5-fluorouracil treatment is prevented by the addition of leucovorin in murine colon tumors, Cancer Res. 52:4922-4928 (1992).

12. CL Van der Wilt, GWM Visser, BJM Braakhuis et al., In vitro antitumour activity of cis- and trans5-fluoro-5,6-hydro-6-alkoxy-uracils; effect on thymidylate synthesis, Brit $\mathrm{J}$ Cancer 38:702-707 (1993).

13. CL Van der Wilt, K Smid, GW Aherne et al., Evaluation of Immunohistochemical Staining and Activity of Thymidylate Synthase in Cell Lines.In: "Chemistry and Biology of Pteridines and Folates". (Eds. J.E. Ayling, M.G. Nair, C.M. Baugh). Plenum Publishing Corporation, New York. Adv. Exp. Med. Biol. 338; 605-608 (1993).

14. SJ Freemantle, GW Aherne, A Hardcastle et al., Increases in TS protein levels measured using newly developed antibodies, Proc. Am. Assoc. Cancer Res. 32:360 (1991).

15. LL Vindelov and IJ Christensen, A review of techniques and results obtained in one laboratory by an integrated system of methods designed for routine clinical flow cytometric DNA analysis, Cytometry 11:753 (1990).

16. K Keyomarsi, J Samet, G Molnas et al., The thymidylate synthase inhibitor, ICI D1694, overcomes translational detainment of the enzyme, J. Biol. Chem. 268:15142-15149 (1993).

17. SJ Freemantle, $J$ Lunec, $C L$ Van der Wilt et al., Polymerase chain reaction quantification of thymidylate synthase (TS) mRNA levels in tumour samples of patients recently treated with 5fluorouracil (5-FU) \pm leucovorin (LV). Proc. Amer. Assoc. Cancer Res. 34; 348 (Abstract 2076) (1993).

18. M Kashani-Sabet, JJ Rossi, Y lu et al., Detection of drug resistance in human tumors by in vitro enzymatic amplification, Cancer Res 48:5775-5778 (1988).

19. LG Navelgund, C Rossana, AJ Muench, LF Johnson, Cell cycle regulation of thymidylate synthase gene expression in cultured mouse fibroblasts, I. Biol. Chem. 255:7386-7390 (1980). 